\title{
UNA RECONSTRUCCIÓN CRÍTICA DEL ASPECTO NEGATIVO DE LA TEORÍA DEL DERECHO EN HANS KELSEN*
}

\author{
Javier Wilenmann ** \\ Universidad Adolfo Ibáñez, Chile
}

\begin{abstract}
RESUMEN. El presente artículo presenta una reconstrucción crítica de la obra de Hans KELSEN. Una interpretación adecuada de la teoría de KELSEN permite distinguir en ella dos estadios: i) un primer estadio lógico constituido por la formulación de un programa científico alrededor de su teoría de la validez y de la estructura de la norma, y un segundo estadio consistente en la realización de ese programa, el que puede ser dividido a su vez en dos fases, a saber: ii) una fase de realización negativa a través de la generación de una crítica radical a las concepciones tradicionales de la ciencia jurídica incompatibles con el primer estadio, y iii) en una fase de realización positiva, cuyo fruto más relevante es la generación de un esquema completo de comprensión del derecho como un sistema dinámico en constante auto-reproducción. El objeto del artículo es dar cuenta de la formulación del programa y, como ilustración de su forma de funcionamiento, de la lógica de realización de la etapa negativa.
\end{abstract}

Palabras claves: Teoría del derecho, positivismo jurídico, validez, norma, interpretación, derecho subjetivo, persona.

\section{A Critical Reconstruction of the Negative Aspect of the Theory of Law in Hans Kelsen}

ABSTRACT. The paper carries out a critical reconstruction of Hans KELSEN'S theory of law. According to it, KELSEN'S work can be divided in three logical steps: i) the construction of a scientific program, which is formed by KELSEN'S theory of validity and by his understanding of the structure of the legal norm; and the realization of this program, which itself can be divided in ii) a negative step and iii) a positive step. The negative realization of the program comprises KELSEN'S radical critic on the traditional concepts of jurisprudence and legal reasoning, while the positive realization of the program consists on the development of a whole model whose aim is the understanding of the legal order as a dynamic system which regulates and carries out constantly its own reproduction. The paper attempts to present a reconstruction of both the core of KELSEN'S program and the negative step of its realization.

Keywords: Theory of law, legal positivism, validity, norm, interpretation, subjective right, legal person.

* Fecha de recepción: 8 de septiembre de 2015. Fecha de aceptación: 1 de marzo de 2016.

Una versión extendida de este artículo fue presentada y discutida en un seminario interno de profesores en la Universidad de Chile. Le agradezco a los participantes del seminario (Constanza SALGADO, Matías GUILOFF, Juan Pablo MAÑALICH y Jonatan VALENZUELA) por sus muy valiosas contribuciones.

*** Profesor de la Facultad de Derecho de la Universidad Adolfo Ibáñez. LLM Universität Regensburg. Doctor Iuris Albert Ludwigs Universität Freiburg. Correo electrónico, javier.wilenmann@uai.cl. 


\section{INTRODUCCIÓN}

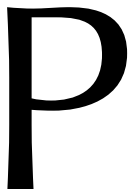

ese a su estatus indubitado de clásico de la ciencia jurídica y de la teoría del derecho, la obra de Hans KELSEN ya no goza de la enorme influencia que ejerció en el pasado sobre el discurso teórico jurídico en el mundo hispano parlante. La normalización del positivismo jurídico y la influencia que ha pasado a ejercer el positivismo de orientación analítica anglosajón han limitado su influencia. La obra de KELSEN y de su escuela de Viena sigue siendo, sin embargo, el intento histórico más radical y profundo de transformación de nuestra percepción del derecho a partir de la disolución de categorías que, en su concepción, no tendrían valor cognitivo. Si ese intento fue fecundo y exitoso, o si la obra de KELSEN habría construido en realidad una algo absurda teoría del derecho sin derecho, «una teoría del Estado sin Estado» (HeLLER, 1992: 23) ${ }^{1}$, es algo que no se deja evaluar de forma sencilla. La enorme magnitud de la obra de KELSEN no alcanza, por una parte, a ser percibida de entrada a causa de la completa interdependencia de sus elementos. El análisis particular de algunas de sus más famosas figuras argumentativas hace perder de vista el carácter holístico de su obra ${ }^{2}$. Por otra parte, la influencia del positivismo jurídico analítico ha tendido a crear un parentesco que es al menos parcialmente ilusorio con KELSEN. Como la obra de KELSEN necesita de percepción global para ser completamente comprendida en sus pretensiones, este parentesco también atenta contra su posibilidad de comprensión completa y de utilización correcta en debates jurídicos actuales.

El objeto del presente artículo se entiende a la luz de este contexto. Su objeto no es analizar algunas construcciones particulares de la obra de KELSEN, sino presentarla como proyecto global, con el fin de dar cuenta de su enorme potencial esclarecedor y de las limitaciones que, al mismo tiempo, un proyecto de esa clase supone. Aunque describir completamente ese proyecto en un artículo resulta imposible, sí es en cambio posible presentar los lineamientos generales y los argumentos centrales del proyecto global. Ello solo puede tener lugar, sin embargo, a partir de una interpretación: el texto presenta, de esta forma, argumentos a favor de una interpretación global de la obra de KELSEN que puede ser designada como neokantiana y desontologizada, sin poder tematizar en detalle sus alternativas.

La lectura que se presenta aquí de la obra de KELSEN se basa en una comprensión pragmático-científica que identifica dos estadios lógicos - formulación del programa y realización del programa- y dos fases en el segundo estadio lógico. La teoría de la validez de KELSEN (o su ontología de las normas, o la distinción entre ser y deber, todas descripciones que se refieren al mismo objeto) constituye, bajo esta lectura, el primer estadio lógico de la obra y cumple la función de definir su programa científico. La realización del programa así definido se desarrolla a su vez en dos etapas: una etapa de realización negativa, caracterizada por la crítica a los conceptos tradicionales de la ciencia del derecho a partir de los fundamentos del programa kelseniano; y una etapa de realización positiva, en la que los mismos conceptos criticados son redefinidos o

\footnotetext{
1 Al respecto, con mayor detalle, vid. KORB, 2010: 152 y ss.

2 Similar Ruiz Manero, 2010: 38: «Podríamos decir que desde [...] 1911 hasta la póstuma Teoría General de las Normas [...], KELSEN no dejó de reescribir, una y otra vez, en cierto sentido, el mismo libro».
} 
tematizados mediante conceptos compatibles con las definiciones del programa. El presente artículo pretende entregar una interpretación del núcleo del programa de KELSEN (2), e ilustrar su pretensión de realización crítica («etapa negativa») en la exposición de la forma en que la crítica se desenvuelve respecto a tres conceptos centrales a las ciencias jurídicas: los conceptos de derecho subjetivo, persona e interpretación (3). El artículo no tematiza, en cambio, la realización positiva del programa a partir de la exposición de una teoría del derecho centrada en su carácter dinámico. Si bien ello es, por cierto, relevante, la ilustración del objeto de la obra de KELSEN como programa global parece más nítida al concentrarse en sus aspectos negativos: su obra es ante todo un desafío a un modo de comprensión y estudio del derecho que hasta el día de hoy resulta tradicional.

\section{EL PROGRAMA DE KELSEN: LA TEORÍA DE LA VALIDEZ EN KELSEN COMO EXPRESIÓN DE UNA METAFÍSICA AGNÓSTICA}

La reducción de la obra de KELSEN a una pretensión solo puede ser expresada con una fórmula de esta clase: eliminar conceptos sin potencial cognitivo derivados en general de una metafísica que este consideraba implausible, y sustituirlos por conceptos con sustento epistemológico ${ }^{3}$. Todas las demás pretensiones específicas pueden ser reducidas a esa idea general. Por eso, el punto de partida en la comprensión del proyecto global de KELSEN tiene que ser su teoría de la validez: ella le da fundamentos a su voluntad programática. Solo el KELSEN metafísico permite comprender correctamente la obra anti-metafísica de KELSEN.

\subsection{Ontología de las normas y dualismo metodológico como núcleo programático}

Buena parte de los escritos centrales de la obra temprana de KELSEN consisten en tematizaciones y explicaciones de su comprensión de la distinción entre ser y deber y de la influencia que una comprensión correcta de la tesis tendría en el estudio del derecho.

Esta distinción es, en primer lugar, una tesis sobre aquello que no puede ser el conocimiento jurídico: no puede ser ni reducción a la observación de fenómenos empíricos (naturalismo) ni postulación de existencia real de otra sustancia metafísica (derecho natural). Esa tesis negativa contiene, por ello: i) una afirmación epistemológica pluralista (aunque, como veremos, el pluralismo de KELSEN es, en realidad, una reducción dualista), y ii) una afirmación metafísica reduccionista. Las dos afirmaciones pueden ser descritas, de forma general, por medio la siguiente fórmula: existen dos formas válidas de generación de conocimiento, pero el mundo tiene una sola sustancia real, por lo que el objeto de referencia de ese conocimiento doble es solo uno. Entender este cruce entre una epistemología dualista y una metafísica monista es crucial para evitar malentendidos relativos a la distinción entre ser y deber.

\footnotetext{
3 Así, por ejemplo, en sus descripciones generales de su pretensión teórica en la segunda edición de los Problemas Capitales (KELSEN, 1923: xxxix-xli) y en la Teoría General del Estado (KelsEN, 1925: xviii). Similar DREIER, 1990: 23.
} 
i) El pluralismo epistemológico puede ser observado ya en la tesis negativa contraria al reduccionismo de la sociología jurídica (o del realismo jurídico). Al igual que buena parte de la obra de KELSEN, su pluralismo epistemológico es en primer lugar una tesis reactiva: el realismo jurídico, la tesis de que el derecho solo puede ser conocido de la misma forma que las ciencias empíricas, es falso. La pugna de KELSEN se centra, en este ámbito, en una impugnación de las premisas del realismo. En materia de conocimiento jurídico, la tesis de que este puede ser reducido estructuralmente a enunciados que tienen una forma equivalente a los enunciados de las ciencias empíricas y que, por ello, pueden ser verificados o falseados por observación de la realidad, solo podría ser correcta si el conocimiento solo pudiera tener lugar mediante procesos de generalización empírica. La obra de KELSEN discute la validez de la pretensión excluyente de la comprensión del conocimiento derivada de las ciencias empíricas: si bien este se encuentra fundado en su ámbito, su aplicación a la comprensión del derecho implicaría incomprensión de su objeto.

ii) El reduccionismo metafísico, crucial en la obra de KELSEN, puede parecer a primera vista incompatible con su pluralismo epistemológico y tiende, a su vez, a ser mal comprendido por la constante utilización de expresiones en la descripción de la distinción entre ser y deber que parecen concederle un sustento real ${ }^{4}$ (ante todo: hablar de dos «reinos», cuestión que ya en KANT es conflictiva) ${ }^{5}$. Una comprensión de esta clase, sin embargo, no solo es incompatible con su teoría del conocimiento jurídico, sino que el propio KELSEN insiste recurrentemente en su incorrección al reconstruir la distinción entre ser y deber ${ }^{6}$.

En realidad, la teoría del conocimiento jurídico de KELSEN, y derivativamente su teoría de la validez, constituyen adaptaciones sencillas de tópicos generales del neokantismo $^{7}$. La teoría del conocimiento jurídico de KELSEN se basa en la creencia general neokantiana de que el conocimiento es ordenación con sentido de datos externos y que esa ordenación es una prestación del sujeto. Para que la ordenación con sentido pueda ser compartida, ella debe tener lugar por medio de la aplicación de principios intersubjetivos comunes. Así, la correcta aplicación de estos principios (esto es lo que KaNT y posteriormente los neokantianos, incluyendo al propio KELSEN, llamarían «juicios») ${ }^{8}$ es el conocimiento. El objeto del conocimiento no es por ello directamente la materia (el mundo), sino juicios efectuados a su respecto. La validez de dichos juicios, y por ello la justificación del conocimiento, dependerían así de la correcta aplicación de principios sintéticos. Así, por ejemplo, en el conocimiento de la forma de organización

4 Representativo GUASTINI, 1999: 257.

5 Las citas, por ejemplo, a COHEN y la distinción entre reino de la realidad y de la normatividad, postulada ya en su escrito de habilitación para explicar la diferencia entre ser y deber, pueden hacer pensar en la creencia en la existencia de una cierta ontología dualista que fundaría la distinción. Al mismo tiempo, la insistencia en la formulación de la teoría de la norma fundante básica en la completa falta de relación entre ser y deber también puede hacer pensar en que la expresión «dos reinos distintos», utilizada en la descripción de la oposición ser y deber, tiene sustento ontológico. Si esto es así o no es solo un problema menor. Es, en cambio, claro que la validez no es en sí expresiva de nada real; si existe diferencia ontológica entre validez y realidad, esa diferencia no implica el postulado de una segunda sustancia, sino solo la negación de la segunda (lo válido no es real). Al respecto, vid. también HeIDEMANN, 1997: 25; y PAULSON, 2005: 206-210.

6 Así ya explícitamente en KELSEN, 1916: 38.

7 Sobre la falta de identidad con los postulados centrales de las dos grandes escuelas neokantianas, vid. WiLENMANN, 2014: 54 y ss.

8 KELSEN, 1923: xl. 
interna y externa de la materia, la aplicación del principio de causalidad constituye a la naturaleza; conocimiento correcto sobre el mundo natural es aplicación correcta del principio de causalidad en la elaboración de juicios causales ${ }^{9}$. No se trata, por ello, de que exista una oposición entre realidad y normatividad, sino más bien entre naturaleza, entendida como interpretación de la realidad a partir de aplicación del principio de causalidad, y derecho, esto es, la interpretación de la realidad a partir del principio de imputación. «El dualismo fundamental se encuentra constituido por una diferenciación total en la mirada teórico-cognitiva» ${ }^{10}$.

Por supuesto, la tesis neokantiana sobre la generación de la realidad con sentido como prestación subjetiva es lógicamente compatible con la tesis epistemológica reduccionista que KELSEN pretende combatir: el naturalismo. Una teoría naturalista neokantiana de esta clase tendría que afirmar que el único principio sintético realmente compartido y, de este modo, con rendimiento cognitivo, es el principio de causalidad ${ }^{11}$. Parte importante de la obra temprana de KELSEN pretende combatir esta afirmación al postular la existencia de un segundo principio sintético, pero su argumentación a este respecto es más bien oscura. De acuerdo a KELSEN, sería posible reconocer no uno (principio de causalidad) sino dos (principio de imputación) principios sintéticos con rendimiento cognitivo, por lo que el conocimiento obtenido de la aplicación correcta del principio de imputación —el conocimiento jurídico— también sería conocimiento científico $^{12}$. Qué significa esto y qué permite atribuirle el status de principio sintético al principio de imputación, es algo que no es inmediatamente claro en la obra de KELSEN. Si el principio de imputación, por ejemplo, fuera exclusivamente una estructura de pensamiento («si $x, y$ debe ser»), su aplicación sería posible más allá del derecho. No hay nada que impida pensar, por ejemplo, una moral con una estructura asimilable al principio de imputación: si una acción moralmente incorrecta tiene lugar, entonces debe ser expresado reproche. El principio de imputación es, sin embargo, postulado como estructura con mérito cognitivo solo respecto del derecho. No se trata, por ello, de que la generación de conocimiento sea posible por la estructura del principio de imputación, sino que su aplicación en la comprensión del derecho positivo es aquello que permite obtener conocimiento científico.

Ello quiere decir que la concesión de valor científico al conocimiento jurídico no se funda, como puede aparecer de una lectura superficial de la obra de KELSEN, en el principio de imputación, sino que se funda en la comprensión común general del fenómeno derecho positivo ${ }^{13}$. El agnosticismo metafísico de KELSEN se revela aquí en toda su magnitud: en la creencia en que nuestra limitación en la interpretación común

9 Similar HeidemanN, 1997: 18; 2000: 265; PAULSON, 2006: 533-534.

10 KELSEN, 1916: 37.

11 Ni siquiera Hermann COHEN, sin embargo, tenía una comprensión de esta clase. En COHEN los métodos de generación de conocimiento son válidos en la medida en que sus aplicaciones tengan sustento racional. Ese es el caso, por cierto, de las ciencias empíricas, pero también de las matemáticas y de la ciencia jurídica. Precisamente por ello es que la lógica y la ética tendrían también valor cognitivo.

12 Vid., por ejemplo, KELSEN, 1928: 273 y ss.

13 El reconocimiento de KELSEN de que su obra se enmarca, ante todo, en la tradición de K. F. VON GERBER, P. LABAND y G. JELLINEK - los grandes impulsores de una forma de positivismo en la dogmática del derecho público en Alemania_, en la Teoría General del Estado (KELSEN, 1925: xvii), también es demostrativa de esto. 
de la realidad a la interpretación causal solo es superada gracias al factum del derecho positivo, esto es, gracias a la capacidad de reconocimiento de deberes válidos a partir de un conjunto de convenciones reales que permiten dicha interpretación ${ }^{14}$. No se trata, de este modo, de que el principio de imputación tenga una entidad particular que asegure el carácter científico del derecho; al contrario, el principio de imputación no es más que la estructura del derecho positivo mismo y su aplicación solo es científica cuando es aplicada a él. Por lo mismo, no se trata de que exista algo así como un principio a priori inserto en nuestro entendimiento; al contrario, nuestro entendimiento objetivo del derecho se encuentra fundado en la existencia del derecho positivo, cuya comprensión correcta supone la asunción de algo así como el principio de imputación.

KELSEN jamás lo habría expresado de esta forma, porque alegaría que una descripción de esta clase supone una cierta confusión entre ser y deber, pero en el fondo en su obra no hay más que una comprensión pragmática (o «constructivista») sofisticada del derecho: la idea de que el derecho positivo forma un segundo reino de conocimiento, el deber, conformado por los propios sujetos que lo conocen, no es más que la afirmación de que el derecho es una práctica de extensión casi universal y que, por lo mismo, se encuentra universalmente extendida en sus postulados generales de reconocimiento de la práctica ${ }^{15}$.

\section{2. ¿La ciencia reducida a las ciencias naturales y a las ciencias jurídicas?}

La teoría del conocimiento de KELSEN no solo excluye cualquier posibilidad de conocimiento normativo más allá del derecho positivo. Su tesis reduccionista va mucho más lejos: solo el conocimiento de la naturaleza a partir de la ordenación de la materia mediante el principio de causalidad y el conocimiento del derecho positivo a partir de su ordenación mediante el principio de imputación pueden ser considerados científicos.

En la tesis de KELSEN es así posible reconocer dos tipos de reducciones: un dualismo metodológico y un escepticismo ético. La segunda reducción ${ }^{16}$, si bien sumamente controversial, constituye un tópico comúnmente discutido en la filosofía desde la Antigüedad. La idea de que el conocimiento normativo moral no tiene al menos el mismo status que el conocimiento empírico causal no es autoevidente, pero tiene verosimilitud y goza de una amplia popularidad en la filosofía. En cambio, la idea de que más allá del popular conocimiento científico natural el único conocimiento científico posible sea el conocimiento jurídico solo puede parecer extravagante ${ }^{17}$. Los propios

14 Vid. la clara exposición de la pretensión agnóstica del positivismo kelseniano en KELSEN, 1928: 276 y ss.

15 Precisamente lo anterior hace que la famosa crítica de HART a la norma fundante básica, a partir de la reducción de la norma de reconocimiento última a la condición de práctica, no tenga diferencias esenciales con su objeto criticado.

16 En qué medida ese escepticismo ético es compatible con la valoración evidente del potencial de control del derecho constantemente resaltado por KELSEN, es algo que se deja dudar. Así también RuIZ MANERO, 2010: 38 y ss.

17 Casos como las matemáticas o la lógica se ven excluidas, por cierto, de este tratamiento, a causa de su carácter de disciplinas analíticas y no, como las ciencias, sintéticas. Eso no quiere decir, por cierto, que no gocen de una pretensión de racionalidad equiparable o superior a estas. 
neokantianos habrían postulado otros principios antes que el principio de imputación: el principio de finalidad en STAMMLER ${ }^{18}$ o el principio de relevancia como valor de las ciencias culturales en RICKERT ${ }^{19}$ constituyen reconstrucciones metodológicas al menos mucho más extensas que el principio de imputación.

La tesis de KELSEN, sin embargo, parece ser que solo en la interpretación jurídica del mundo puede encontrarse un conjunto de convenciones cuya extensión sea igualmente amplia para asegurar comprensión objetiva común. Esta reducción de KELSEN permite confirmar el punto de la sección anterior: imputación no es un principio metafísico trascendental, sino un presupuesto pragmático trascendental de una práctica de extensión casi universal. El argumento a este respecto puede construirse por analogía con las ciencias naturales: el funcionamiento del derecho positivo, o incluso la mera asunción de su existencia, suponen un conjunto de convenciones interpretativas comunes de la realidad que hace posible la síntesis de forma equivalente a la constitución común de la naturaleza. Esas asunciones podrían ser tratadas correctamente como existentes porque el derecho funcionaría en su capacidad de entregar un marco de comprensión común, por lo que el conocimiento jurídico debiera ser considerado científico $^{20}$.

Pese a la aparente extravagancia del dualismo epistemológico de KELSEN, este es central en su obra. Buena parte del contenido de su teoría del derecho tiene por objeto disolver aquello que no es compatible con la estructura básica de la comprensión común del derecho positivo: los conceptos eliminados y disueltos, en general, en la estructura de la norma, lo son por tener un supuesto carácter metafísico incompatible con el conocimiento posible revelado por su teoría del conocimiento.

\subsection{Validez como compromiso ideológico objetivo común: el principio de imputación y la norma fundante básica}

La teoría de la validez de KELSEN es una producción de su teoría del conocimiento. Válidos son los enunciados normativos que implican correcta aplicación del principio de imputación a su objeto, es decir, todos aquellos enunciados normativos que integran al derecho positivo. Como los enunciados normativos solo pueden ser científicamente conocidos bajo existencia de un conjunto de convenciones que lo garantice (el derecho positivo), la afirmación de la validez implica lógicamente la afirmación de la obligatoriedad del enunciado normativo en cuestión y asimismo implica lógicamente pertenencia a un sistema jurídico positivo. El concepto de validez aparece así caracterizado en la obra de KELSEN: validez es a veces descrita como obligatoriedad ${ }^{21}$ (o «existencia» de la norma) ${ }^{22}$, pero en su tratamiento es explicado a partir de la pertenencia al ordenamiento jurídico ${ }^{23}$. Si bien esta multiplicidad de caracterizaciones de la validez

\footnotetext{
18 Vid. STAMMLER, 1925: 400 y ss.

19 Vid. RICKERT, 1926: 81 y ss.

$20 \mathrm{Al}$ respecto, vid. solo HeIDEMAnN, 1997: 46 y ss.; y WilenManN, 2014: 55 y ss. con nota 49.

${ }^{21}$ KeLSEN, 1960: 196.

22 Ibid., 9.

${ }^{23}$ Ibid., 196 y ss.
} 
tiende a ser criticada a causa de una supuesta inconsistencia, en realidad se trata de conclusiones que son interdependientes en el sistema de KELSEN.

Esta interdependencia se confirma cuando uno reconoce el carácter circular de la construcción. Considerado estáticamente, el juicio de validez es obtenido a partir de aplicación correcta del principio de imputación. Con ello, la estructura del objeto respecto del cual puede afirmarse su validez es la estructura de una regla. Pero esa descripción de la validez supone ya la conformación del objeto del que se quiere obtener conocimiento (el derecho positivo), lo que en el ámbito del derecho positivo tiene lugar mediante una prestación anterior que también tiene la forma de la aplicación del mismo principio sintético y que también se integra en el conjunto de convenciones que constituyen al propio objeto. En esto, conocimiento científico natural y conocimiento científico normativo se diferencian claramente: mientras el objeto del primero es asumido como independiente de los actos que permiten su conocimiento, el objeto del segundo se integra en el esquema de los mismos actos que permiten su conocimiento. Hablar del todo de un objeto «derecho positivo» que pueda ser conocido normativamente implica postular la posibilidad de conocimiento normativo, el que depende a su vez de la existencia de un objeto cuyo conocimiento tenga la forma del conocimiento normativo, todo lo cual es circular ${ }^{24}$. La estructura circular de este postulado es la norma fundante básica: como la posibilidad del derecho depende de la posibilidad de su conocimiento, pero la posibilidad de su conocimiento depende a su vez de la existencia del derecho mismo, el fundamento de la validez del derecho solo puede encontrarse en la afirmación dogmática de la existencia de la convención ${ }^{25}$. La norma fundante básica es así la explicitación del compromiso ideológico común que constituye al derecho positivo.

Por supuesto, en la Teoría Pura del Derecho, el postulado de la existencia de una norma fundante básica no es efectuado a partir de reflexiones sobre las relaciones entre conocimiento normativo y conformación del objeto de conocimiento, sino a partir de una reflexión sobre la conformación dinámica de un sistema de normas válidas y, con ello, asume una estructura temporal y no estática ${ }^{26}$. Pero la expresión dinámica de la norma fundante básica es en realidad un resultado de la propia estructura circular de la comprensión de KELSEN de la validez del derecho positivo. Es precisamente el hecho de que la validez sea la expresión de una comprensión sintética común manifestada en el reconocimiento de un objeto normativo dependiente de esa comprensión común, la que a su vez solo tiene sentido en relación con ese objeto conformado por ella, la que hace que la validez tenga que ser dogmáticamente postulada ${ }^{27}$. Ello ciertamente se hace mucho más fácil de ver cuando uno reconstruye las cadenas de validez como

24 Sobre la diferencia del conocimiento en ámbitos que pueden ser reconstruidos a partir de una pragmática descriptiva respecto de otra clase de pragmática (en general ligada a una deontología), vid. SEARLE, 2010: 73 y ss.

25 En el fondo similar AleXY, 1992: 143: «El problema interno [del concepto jurídico de validez] se deriva del hecho de que la validez jurídica presupone validez jurídica y parece, por ello, ser circular. ¿De qué otra forma puede ser descrito un "órgano competente" o la promulgación de la ley "en la forma prevista para ella"?».

26 En todo, vid. KELSEN, 1960: 200 y ss.

27 Este carácter de postulación dogmática y no justificable es, por cierto, ampliamente admitido por el propio KELSEN. Así, por ejemplo, KELSEN ,1928b: 278. 
KELSEN, pero pese a la mayor claridad de la exposición dinámica de esta consecuencia, su origen se encuentra en la comprensión misma de la validez. Esto es obvio a causa de la necesidad de reconocer una norma fundante básica no solo en sistemas dinámicos, sino también en sistemas estáticos, algo que es reconocido explícitamente por el propio KELSEN ${ }^{28}$. Por ello, la caracterización de la norma fundante básica como presupuesto lógico trascendental ${ }^{29}$ no es completamente precisa. El método trascendental supone una diferenciación entre el objeto cuya existencia se da por cierta y el objeto cuya existencia se deduce de la necesidad de la forma del primer objeto. En el caso de la norma fundante básica, ella especifica una condición bajo la cual el objeto tiene lugar del todo: sin asunción común de la comprensión normativa del mundo el derecho no es simplemente un noúmeno inaccesible, sino que simplemente no tendría existencia.

Lo anterior permite comprender un aspecto de la Teoría Pura que tiende a ser erróneamente criticado, a saber, la supuesta confusión categorial que se encontraría implicada en el tratamiento de la eficacia en la obra de Kelsen. Como es sabido, KELSEN sostiene en la Teoría Pura del Derecho que la validez de las normas solo puede postularse respecto de un sistema generalmente eficaz ${ }^{30}$. No es poco común encontrar críticas a KELSEN, en el sentido de que esa afirmación implicaría reconocimiento de la falsedad (o traición) del postulado de distinción lógica entre ser y deber ${ }^{31}$. Sin embargo, esa afirmación no contradice la distinción (en la forma en la que es postulada por KELSEN), sino que se deduce de ella. Como el conocimiento normativo solo es posible allí donde existen convenciones comunes que permitan postular un principio sintético con extensión suficiente para ello, y solo el derecho positivo expresa esto, el deber solo puede existir allí donde haya eficacia de un sistema jurídico. O, expuesto en términos pragmáticos, el postulado de la verdad de las condiciones de sentido de una práctica solo tiene él mismo sentido ante existencia de la práctica.

\subsection{La estructura de la norma (el principio de imputación) como categoría objetiva excluyente de conocimiento jurídico. Sobre la acusación de logicismo}

La teoría del conocimiento jurídico de KELSEN tiene una pretensión parcialmente metafísica, pero sus consecuencias centrales son estructurales y metodológicas. Es esta clase de consecuencias aquello que, como veremos, tiene incidencia directa en la etapa de realización negativa del programa. Las consecuencias en cuestión pueden ser fácilmente explicadas del siguiente modo: en tanto teoría metafísica, la teoría de KELSEN supone una cierta ontología de las normas y de la validez. Las normas serían el sentido de actos interpretados a través de normas que a su vez les otorgan sentido ${ }^{32}$, todo lo cual podría ser reducido a la estructura de la imputación. La teoría del conocimiento jurídico permite, en primer término, justificar esta comprensión de las normas. Pero, al mismo tiempo, ella tiene una pretensión de limitación en la comprensión del derecho:

28 KeLSEN, 1960: 198 y ss.

29 Ibid., 204 y ss.

30 Ibid., 218 y ss.

31 Así por ejemplo Buligyn, 2005: 81. La misma crítica tiende a plantearse respecto de la idea, expuesta en la segunda edición de la Teoría Pura del Derecho, de enunciados descriptivos de deber ser.

32 Kelsen, 1960: 3 y ss. 
como aquello cuyo conocimiento normativo es posible tiene la estructura de la norma, el conocimiento del derecho se agota en enunciados normativos que puedan tener esta estructura. La idea de que el conocimiento del derecho tiene que reducirse a esta estructura, la que en tanto estructura «objetiva» y con contenido determinado permitiría manejo científico, es un tópico que se encuentra presente en la obra de KELSEN desde los Hauptprobleme.

La estructura de la norma en KELSEN es homogénea. No toda proposición que incluya el verbo «deber» es una norma, sino que el deber tiene que encontrarse especificado por una sanción. Una regla del tipo «no debes matar» no es una norma (primaria) en sentido kelseniano. Norma solo es la proposición que indica que a un supuesto de hecho determinado debe seguirle una consecuencia, con lo que se dirige principalmente a los funcionarios encargados de su aplicación (jueces). La distinción puede ser sencillamente explicada por medio de la comparación de dos formas de comprensión de normas penales. Así, la norma que instituye el delito de homicidio puede ser considerada una prohibición de matar, pero es también un mandato de aplicación de un castigo en caso de verificarse un homicidio. De acuerdo a KELSEN, solo la segunda proposición es una norma real. Por supuesto, la aplicación de la pena solo tiene sentido si el autor efectivamente mató a otro, con lo que la postulación de una norma secundaria del tipo «está prohibido matar» no es absurda —al contrario, se encuentra implícita al postular un vínculo de imputación entre la aplicación de la sanción penal y el sujeto- ${ }^{33}$, pero su existencia sería superviniente al establecimiento de la obligación de sancionar ${ }^{34}$. Esto, de nuevo, muestra la dependencia de la teoría del derecho de KELSEN de una práctica en funcionamiento, a saber, el derecho moderno y la institucionalización de la coacción en organismos estatales. El objeto de la teoría es la reconstrucción racional del fenómeno moderno de regulación positiva del uso estatal de la coacción.

La pretensión de reducir el estudio del derecho a la explicitación de enunciados normativos de este tipo requiere, por cierto, de fundamentación. Por una parte, no es inmediatamente claro qué hace que solo las normas con esta estructura sean cognoscibles. Una teoría de las normas dualista, por ejemplo, puede pretender postular al mismo nivel de objetividad. El tipo de críticas que a este respecto pueden formularse a KELSEN (o, al menos, a algunos de sus seguidores) son conocidas: una teoría de esta clase no permitiría distinguir entre impuestos y sanciones, lo que daría cuenta de inverosimilitud en su capacidad de descripción del derecho ${ }^{35}$. La discusión a este respecto es puramente estructural. Pero, por otra parte, la pretensión de la reducción del estudio del derecho a la explicitación descriptiva de enunciados normativos implica necesariamente dejar fuera de consideración otros tipos de problemas — por ejemplo, problemas de fundamentación en sentido estricto de interpretaciones, algo expresamente reconocido por KELSEN-, con total independencia de que la teoría de las normas caiga, o no, en el monismo kelseniano. La primera crítica depende, por ello, de una discusión metodológica de precisión. La segunda crítica trasciende este aspecto y vuelve, con ello, a la discusión del núcleo del programa de KELSEN.

\footnotetext{
33 Ibid., 120 y ss.

34 Ibid., 116 y ss., y 120 y ss.

35 Vid., por ejemplo, RENZIKOWSKI, 2001: 110 y ss.; o RUIZ MANERO, 2010: 42.
} 
En la discusión de las teorías de KELSEN, la segunda crítica ha sido, con buenas razones, más relevante. Sus consecuencias son mucho más radicales que las limitaciones estructurales a las que apunta el primer tipo de críticas. No solo los problemas de legitimación del sistema en general quedan fuera de consideración propiamente jurídica, sino que el estudio del sentido de las instituciones es desplazado fuera del ámbito de la ciencia del derecho. El aislamiento de KELSEN durante la discusión de teoría del Estado y teoría del derecho en Weimar es el resultado, en buena medida, de esta reducción. La descripción de Erich KAUfMANN en 1921 es a este respecto ilustrativa:

Solo una metafísica radicalmente logicista pueda fundar el convencimiento de Kelsen de que el ideal del monismo jurídico universal puede aportar en algo a su realización. [...] La metafísica de este logicismo racionalista tiene algo tan grotesco que se convierte en algo casi grandioso. (KAUfMANN, 1921: 29).

El tipo de razones que explica la asunción de una metodología con este nivel de radicalidad es variado. Pero, en el nivel interno de la teoría, su radicalidad se presenta como una derivación directa de los fundamentos de esta. Así, buena parte de las críticas expuestas por KELSEN a conceptos de la ciencia del derecho que exceden este umbral se refieren a su falta de contenido real y, ante todo, a su supuesto contenido ideológico ${ }^{36}$. Esto es, buena parte de los conceptos de la ciencia del derecho que son destruidos o reconstruidos objetivamente por KELSEN son así atacados en dos frentes: KELSEN pretende demostrar que tienen tanto un contenido ideológico inmanente (son conceptos morales) como un sustrato fáctico incompatible con la metodología del derecho (típicamente sucede esto con conceptos con contenido psicológico), o al menos uno de ellos. La realización negativa del programa es, en lo esencial, esta especie de batalla en dos frentes librada por KELSEN. El ejemplo más evidente a este respecto se da en la crítica a la idea de derecho subjetivo ${ }^{37}$.

En el lenguaje kelseniano, es por ello usual encontrar calificaciones peyorativas construidas a partir de estos dos modos alternativos de privación de status objetivo a tesis rivales, a saber, naturalismo o ideología. Ambas críticas se vinculan ciertamente a obsesiones de KELSEN desde sus trabajos tempranos, pero en la formulación de su programa se derivan directamente de algunos de sus postulados centrales. La crítica de naturalismo deriva, obviamente, de su concepción de la distinción radical entre ser y deber. La crítica de ideología (o de «metafísica») es el correlato de su concepto de objetividad y cientificidad: aquello que no puede ser sintéticamente determinado no es objetivo ni científico, por lo que las discusiones a este respecto son ideológicas, es decir, relativas a intereses y, en cualquier caso, no adjudicables. El escepticismo moral, que en principio parece derivarse de la teoría del conocimiento jurídico, viene de esta forma a servir de sustento a las limitaciones que impone esta teoría del conocimiento. Por lo mismo, este requiere de fundamentación independiente. En esto, los argumentos que KELSEN entrega para sostener su comprensión escéptica no son particularmente convincentes, y recuerdan mucho más que otras construcciones de KELSEN a la pura búsqueda de certeza del positivismo tradicional. En buena medida,

\footnotetext{
$36 \mathrm{Al}$ respecto, vid. solo DreIER, 1990: 27 y ss.; y PAULSON, 1990: 160 y ss.

$37 \mathrm{Al}$ respecto, con más detalle, HAMmER, 2005: 176 y ss.
} 
la crítica de KELSEN se concentra en la pretensión de la tradición del derecho natural de desconocer el carácter de derecho a normas o sistemas injustos. Según KelSEN, el tipo de actitud al que esta pretensión lleva sería especialmente acrítico: siempre serían sistemas jurídicos ajenos, pasados o hipotéticos aquellos que no merecerían reconocimiento $^{38}$. Si bien esta observación sociológica tiene cierto correlato histórico ${ }^{39}$, la crítica se refiere solo a la pretensión más inverosímil de los defensores de alguna clase de optimismo ético. En la cuestión específica, por ejemplo, de la relevancia de los argumentos al menos parcialmente morales en la interpretación, el argumento no tiene el mismo peso.

La fijación de KELSEN en el combate a la supuesta ideología que anima a la jurisprudencia que no separa derecho y moral se ve fundada, paradójicamente, en una representación ética, a saber, la idea de que el valor central del derecho moderno se encontraría en el otorgamiento de certeza y protección ${ }^{40}$, lo que se deja resumir bajo el concepto de Estado de derecho ${ }^{41}$. En ninguna parte de su obra puede notarse tan nítidamente este espíritu político como en la frase final del que sea probablemente el primer artículo relevante sobre teoría del Estado publicado por KELSEN, Rechtsstaat und Staatsrecht, de 1913. En él, el programa de KELSEN se ve definido oponiendo una concepción legítima del Estado a una concepción autoritaria:

Si uno agrupa estas relaciones bajo el concepto del jus publicum, entonces la oposición entre derecho privado y derecho público es entendida como una oposición entre el derecho verdadero y un no-derecho, el poder libre de derecho, el que falsamente se arrogaría el nombre de derecho. La conservación de estos criterios significa entonces dejar en el Estado de derecho un resabio del Estado policial, una tendencia teórica que no está libre de intenciones políticas. Una sistemática jurídica adecuada a la idea de Estado de derecho todavía no ha sido desarrollada.

Pero la idea de Estado de derecho no ha sido superada, su completo desarrollo lógico es la tarea del futuro (KeLSEN, 1913: 1253) ${ }^{42}$.

Los aspectos fundamentales de la obra de KELSEN, su concepción del conocimiento jurídico y de la validez y, derivativamente, de la ciencia del derecho, definen de esta forma su programa. El programa tiene por objeto otorgarle un carácter verdaderamente científico al derecho, lo que en KELSEN significa disolver y reemplazar todos los conceptos jurídicos capitales que no puedan ser reducidos a la estructura de la norma.

38 KELSEN, 1960: 70-71.

39 Tanto la experiencia europeo-central de KELSEN como la experiencia chilena o argentina durante las dictaduras militares parece confirmar el punto: en ambos casos, buena parte de los conservadores interesados en la defensa de la idea de derecho natural no fueron especialmente críticos con regímenes evidentemente inmorales. Vid., por ejemplo, GARZÓN VALDÉs, 2000: 184.

40 Similar RuIZ MANERO, 2010: 40 y ss.

41 Una interpretación completa de la obra de KELSEN como pretensión de exaltación de ese valor puede encontrarse en VINX, 2007: passim.

42 Buena parte de la frase solo se entiende a la luz de la comprensión tradicional del derecho en el espacio de habla alemana antes de la revolución de 1918. La teoría del Estado y del derecho del Estado tendía a entenderlo como un sujeto libre de derecho. Al respecto, vid. solo MöLleRS, 2008: 15-22. 


\section{HACIA UN DERECHO SIN METAFÍSICA Y SIN IDEOLOGÍA: REFUTACIÓN Y DISOLUCIÓN DE CATEGORÍAS CONFLICTIVAS. EL ASPECTO NEGATIVO DEL DESARROLLO DEL PROGRAMA DE KELSEN}

\subsection{Introducción: el conflicto como método}

Pese a que ya los aspectos de la obra de KELSEN que pueden ser reconstruidos como fundamentación de su programa tienen un contenido polémico, su forma de exposición en estos ámbitos es mucho menos dialógica (y polémica) que en la realización de su programa. En su segundo estadio lógico, no ya la formulación, sino la realización del programa, este tuvo en cambio la forma casi constante de un ataque ${ }^{43}$. Esto es por supuesto consistente con su pretensión de disolución de las categorías tradicionales de la ciencia del derecho ${ }^{44}$. Parte de la pasión científica de KELSEN se nota, sin embargo, en la intensidad del desarrollo de esa polémica ${ }^{45}$.

La estructura dialógica de la realización del aspecto negativo del programa produce, al mismo tiempo, que buena parte de su contenido se juegue en relación con conceptos atacados por KELSEN. En un estudio sin pretensiones de completitud, no es posible referirse a todos los conceptos centrales atacados y redefinidos por KELSEN. Solo pretendo centrarme en tres de ellos para ilustrar la forma en que se desarrolló el programa: el concepto de derecho subjetivo, el concepto de persona y la idea de interpretación. Estos tres casos, que tematizan tanto conceptos sustantivos como procedimientos de la ciencia del derecho, debieran servir como ilustración suficiente de la pretensión negativa de KELSEN.

\subsection{KELSEN frente a la dogmática tradicional del derecho privado: la disolución de la noción de derecho subjetivo en la estructura de la norma}

La función crítica de la comprensión kelseniana del derecho pretendió reconocer ya desde los Hauptprobleme un concepto conflictivo en la noción de derecho subjeti-

43 Vid. KORB, 2010: 2.

44 Similar LEPSIUS, 2013: 242-243.

45 En esto, la cultura jurídica alemana ha retenido ante todo frases particularmente agresivas tomadas del intercambio con Rudolf SMEND. La obra de SMEND, Verfassung und Verfassungsrecht, tendría «una completa falta de consistencia sistemática, una evidente falta de seguridad en su estructuración, la que esquiva la toma de decisiones claras, y prefiere quedarse en alusiones indirectas, cargando cada posición que sea mínimamente comprensible con limitaciones preventivas; más allá de esto, un estilo lingüístico oscuro y pesado, relleno con palabras extrañas que se dejan explicar solo a medias» (KELSEN, 1930: 2). Heinrich TrIEPEL habría por lo mismo descrito el texto crítico de KELSEN como formulado en «un tono excepcionalmente duro, a menudo burlesco e hiriente, lo que no se puede justificar en el hecho que SMEND tampoco haya sido excepcionalmente amable en el trato con opiniones distintas a las suyas». Citado por KORIOTH, 2013: 39. Esto no es, por supuesto, algo que haya ejercido solo KELSEN: a su respecto la polémica también se desarrolló con una intensidad que pudo derivar incluso en antisemitismo. Pese a tener lugar algunos años después del fin de la gran controversia sobre teoría del derecho y del Estado en Alemania, las palabras de Carl SCHMITT al cierre del famoso congreso organizado por este en 1936 sobre «El judaísmo en la ciencia del derecho» son tal vez la más fuerte manifestación de la violencia de la polémica respecto a KELSEN, al recordar «con qué descaro la escuela de Viena del judío Kelsen se citaba solo a sí misma, con qué para nosotros alemanes incomprensible crueldad y falta de vergüenza despreciaban a otras opiniones». 
vo. En tanto concepto central del derecho privado, con pretensiones de extensión al derecho público bajo la forma de derechos subjetivos públicos, la pretensión de disolución del concepto de derecho subjetivo era evidentemente polémica. Esto puede ser confirmado no solo por el reconocimiento del propio KELSEN del carácter crucial que para la ciencia del derecho tiene el concepto de derecho subjetivo ${ }^{46}$, sino por la forma en que la idea de derecho subjetivo fue tratada por este: buena parte del tratamiento se desenvolvió como crítica a exposiciones particularmente influyentes en la historia de la ciencia jurídica.

En los Hauptprobleme algunos de los grandes nombres históricos de la dogmática jurídica alemana aparecen directamente criticados por KELSEN en relación a la noción de derecho subjetivo (ante todo IHERING ${ }^{47}$ y WINDSCHEID ${ }^{48}$, en tanto expositores conspicuos de la teoría del interés y de la teoría de la voluntad, respectivamente). Con posterioridad, la cuestión siguió siendo tematizada en el área de interés directo de Kelsen, el derecho público.

Los problemas que, de acuerdo a KELSEN, pueden observarse en la noción de derecho subjetivo serían de al menos dos clases. Se trataría, por una parte, de problemas estructurales i). Por otra parte, el concepto de derecho subjetivo tendría una semántica realista e ideológica teóricamente inadecuada a un derecho que pretende construirse como objeto de conocimiento ii). Se trata, en este sentido, de aplicaciones directas de los elementos que conforman al núcleo del programa.

i) Las críticas estructurales al concepto de derecho subjetivo son a su vez de dos clases. El problema estructural menos relevante se vería constituido por su falta de conciencia frente al aspecto central que caracterizaría al derecho como orden social, a saber, su calidad de orden coactivo. Dado que la comprensión del derecho debiera expresar su condición de orden coactivo, la construcción de conceptos desligados de la administración de la coacción sería inadecuada de acuerdo a KELSEN. El exceso de fijación en el aspecto facultativo de privados que tendría la noción de derecho subjetivo haría asó olvidar aquello que en definitiva sería verdaderamente reglado por el derecho: la obligación subjetiva coactivamente exigible ${ }^{49}$. Algo similar podría decirse del derecho subjetivo: la propiedad. La caracterización de la propiedad como derecho subjetivo haría perder de vista que lo verdaderamente relevante tiene lugar en la esfera de todos los otros sujetos de derecho, a saber, el reconocimiento de obligaciones generales de abstención a su respecto ${ }^{50}$.

Esta forma de la crítica no es particularmente convincente: que la potestad aparezca como fragmento de la norma o como norma independiente, relevante en la configuración de obligaciones, no es algo decisivo en la capacidad de rendimiento del concepto. Mucho más relevante es, en cambio, una segunda crítica estructural: la noción de derecho subjetivo sería ambigua en relación a aquello que pretendería designar.

46 «No incurrimos, evidentemente, en ninguna exageración si afirmamos que, de todos los conceptos jurídicos fundamentales, es precisamente este del subjetivo el más estudiado, el más discutido en la teoría» (KELSEN, 1987: 494).

47 KELSEN, 1923: 497 y ss.

48 Ibid., 509 y ss.

49 Vid. ibid., 494.

50 Ibid., 496; KeLsen, 1934, 45 y ss. 
Así, el concepto llevaría confusión al designar del mismo modo tanto el correlato de una obligación (un crédito) como la fuente normativa de una obligación cuando ella es creada en ejercicio de potestades privadas concedidas por el derecho (una potestad). El concepto de derecho subjetivo tendría así aplicación tanto para designar derechos personales o reales como para designar facultades normativas relevantes en la generación de obligaciones. Por supuesto, la distinción parece colapsar precisamente en el área de mayor interés para KELSEN, esto es, tratándose de la concesión de la facultad de solicitar la aplicación coactiva de la sanción jurídica mediante el ejercicio de una acción ${ }^{51}$. Pero que la obligación aparezca de esta forma ligada a la facultad de solicitar su cumplimiento coactivo no implicaría que no haya una diferencia lógica: llamar precisamente a todo esto derecho subjetivo es lo que haría ciego a estas diferencias. Y, en lo que sería aún más confuso, la utilización constante del concepto de derecho por parte de la teoría del derecho natural racional para tematizar a la libertad política haría que el concepto termine teniendo una ambigüedad e imprecisión insalvable: la idea de un derecho subjetivo (público) a la libertad, por ejemplo, sería conceptualmente incompatible con la dependencia central del concepto de derecho de la posibilidad de afirmar la existencia de obligaciones exigibles coactivamente ${ }^{52}$.

ii) Por otra parte, el concepto de derecho subjetivo tendría una fijación ideológica y teórica que lo haría jurídicamente deficiente. La fijación ideológica sería apreciable en el origen del concepto. El derecho subjetivo sería la conceptualización de la pretensión de la teoría del derecho natural racional en su reacción al absolutismo, a saber, justificar la fijación de límites políticos al soberano ${ }^{53}$. Esto no solo implicaría el involucramiento de una semántica política en un contexto cuyos conceptos debieran tener pretensiones cognitivas — la confusión estructural antes reseñada sería manifestación de ello—, sino además el mantenimiento de una semántica ligada a un contexto político ajeno. Con ironía, KELSEN citaba a JELLINEK para demostrar su punto: la afirmación de que sin la noción de derechos subjetivos no existiría una comunidad jurídica sino una comunidad conformada exclusivamente por esclavos ${ }^{54}$ puede haber tenido sentido en el contexto político en el que sirvió - la liberación de la burguesía-, pero no tiene literalmente ningún sentido si se la priva de su aspecto político; una comunidad de esclavos es, por cierto, una comunidad jurídica especialmente diferenciada. La idea de derecho subjetivo parece así revelar antes un compromiso con una ideología que dignidad cognitiva ${ }^{55}$.

Por otra parte, tanto la teoría de la voluntad como la teoría del interés demostrarían que al concepto de derecho subjetivo le subyacería una semántica realista —el derecho se origina en un acto volitivo o de deseo- que se encontraría en ruptura con el carácter normativo del derecho. En buena medida, el concepto de derecho subjetivo aparece así como cristalización de las dos tendencias metodológicas que la ciencia del

${ }^{51}$ Esta triple confusión es el centro de la crítica a la teoría de la voluntad. Vid. KeLSEN, 1925: 74.

52 KeLSEN, 1923: 495. Similar KELSEN, 1925: 77-78, quien advierte un ánimo de limitación de las potestades del Estado en la semántica de los derechos subjetivos.

53 KELSEN, 1923: 77-78.

54 KeLSEN, 1925: 78.

55 Esto es un tópico que se mantiene en buena parte de sus escritos anteriores al exilio. También en la primera edición de la Teoría Pura puede reconocerse una crítica de este estilo a los grandes comentaristas del concepto de derecho público, aquí por referencia a otro de los miembros de las pandectas, PuCHTA. KeLSEN, $1934 \mathrm{a}, 42$. 
derecho debiera evitar: realismo, ligado tanto al concepto de interés ${ }^{56}$ como al concepto de voluntad bajo una comprensión psicológica; o metafísica insostenible, ligada a la versión ideológica del concepto de voluntad.

Las dos partes del argumento de crítica a la teoría del derecho subjetivo aparecen de forma ejemplar en la convincente (aunque limitada) crítica a IHERING. De acuerdo a este, derecho subjetivo sería el interés jurídicamente reconocido; el fin protector perseguido por la norma al establecer un derecho. La comprensión de IHERING funcionaría así bajo una contraposición entre medio de protección y objeto de protección $\mathrm{o}$, lo que es lo mismo, entre norma y fundamento ${ }^{57}$. El fin (el interés) sería la sustancia no normativa cuya protección es brindada por las normas ${ }^{58}$. La confusión que KELSEN cree advertir en esta construcción se dejaría resumir en la siguiente proposición: «El derecho es solo forma y no contenido, es protección y no lo protegido» (KELSEN, 1923: 619). Así, en la construcción de la teoría del interés, KELSEN cree reconocer dos problemas: por una parte, un problema estructural al designar con la misma palabra («derecho» objetivo y subjetivo) dos sustancias que la misma teoría reconstruye como distintas (norma y hecho). Lo central sería, sin embargo, su propia inverosimilitud: puede ser que el beneficiado con una potestad reconozca generalmente un interés en ello; también es sumamente probable que la legislación (casi) siempre mire a sustratos fácticos a los que pretenda favorecer. Pero de ello no se deducen dos consecuencias que según KELSEN debieran deducirse si el derecho subjetivo tuviera un vínculo inmanente con intereses: los derechos subjetivos (o, mejor, la facultad de exigir en ciertas condiciones el cumplimiento de obligaciones) se tienen con independencia del interés actual en ellos ${ }^{59} \mathrm{y}$ con independencia incluso de la posibilidad de tener intereses a su respecto; y la tenencia de un interés privado con cierta protección jurídica no implica que ello sea un derecho subjetivo.

En sus consecuencias, buena parte de la crítica de KELSEN a la idea de derecho subjetivo parece ser mucho menos disruptiva de lo que ella misma cree amenazar. En lo esencial, la confusión estructural que KELSEN cree reconocer en la noción de derecho subjetivo implica solo una pretensión de reemplazo por términos más precisos: aquello que quiere expresarse mediante el concepto de derecho subjetivo debiera reemplazarse por un concepto no tenga un sustrato ideológico o psicologizante y que no impida percibir la dimensión coactiva del derecho, siendo así insertable en el esquema de la estructura de la norma. El ejercicio de esta clase de poderes de creación de normas es de este modo reducido a la noción de potestad o poder («Berechtigung»), esto es, a un concepto que no se encuentra en ningún caso en ruptura con la semántica tradicional del derecho ${ }^{60}$.

Pese a la apariencia poco disruptiva del reemplazo estructural de KELSEN, el tipo de conclusiones a las que lleva es resaltado por él mismo: una potestad, en el sentido

56 KELSEN, 1923: 498: «(e)l interés es un sustrato de hecho puramente psíquico y de naturaleza, concretamente, psíquico-individual, acerca de cuya existencia decide, exclusivamente, el estado de ánimo del individuo». Similar KELSEN, 1985: 72.

57 Así también KeLSEN, 2005: 72-73.

58 KELSEN, 1923: 498.

59 Kelsen, 1985: 73.

60 Kelsen, 1985: 74-75. 
de una condición para la aplicación de una consecuencia coactiva, es ante todo el ejercicio de la acción correspondiente, lo que implica que sean equiparadas con potestades privadas que condicionen la aplicabilidad de normas (por ejemplo, de celebrar contratos) ${ }^{61}$. Ello lleva a KeLSEN a una reconstrucción del derecho, y en especial del derecho privado, ligada a la noción romana tradicional de la actio. El derecho estaría conformado así por el conjunto de condiciones que hacen procedente una consecuencia, incluido de forma central el ejercicio oportuno y formalmente procedente por parte de su titular de la acción correspondiente ${ }^{62}$. Esto parece ser un giro casi dramático: el administrativista radical, cuya crítica a las nociones tradicionales legadas por las ciencias del derecho privado y del derecho penal consiste en lo esencial en afirmar que estas debieran ser sustituidas, termina ofreciendo una concepción del derecho basado en acciones, es decir, una noción prácticamente romanista de derecho. Con ello, pese a la vehemencia de la crítica, el potencial de la teoría pura del derecho en este ámbito es limitado: ciertamente permite denunciar ciertas confusiones y, al mismo tiempo, tiene un poder de rendimiento relevante al mostrar la forma en que las potestades privadas se insertan en el derecho, en tanto contexto procedimental de exigencias coactivas, pero no va más allá de esto.

\subsection{Persona e imputación central: la disolución del concepto sustantivo de persona en la estructura de la norma}

$\mathrm{Al}$ igual que respecto de la noción de derecho subjetivo, KELSEN produjo una muy lúcida crítica al concepto de persona. La crítica a la noción de persona servía a KELSEN por varios motivos: ella era relevante no solo como lugar de prueba de representaciones centrales de la dogmática jurídica, sino que al mismo tiempo se trata de un concepto central en el área de interés dogmático directo de KELSEN, el derecho público, por la creencia extendida en que el Estado y sus órganos tienen personalidad. Para KeLSEN, esta representación debía ser inmediatamente llamativa: bajo una comprensión naturalista del concepto de persona, la personalidad del Estado solo podría parecer o bien como ficción o bien como concepto real cuya función es designar la sustancia que se encuentra detrás del ordenamiento jurídico («el soberano»). Esta representación - la idea de que la personalidad requiere sustancia y su traslado al ámbito público en la sustantivización del Estado- sería metodológicamente insostenible de acuerdo a KELSEN ${ }^{63}$ : si el objeto se constituye solo a partir del conocimiento, la distinción entre objeto a conocer y objeto conocido no tendría sentido, de la misma forma en que la tesis de JeLLINEK en relación a que un mismo objeto (el Estado) puede ser conocido de dos formas distintas (sociológica y jurídica), sería incompatible con una teoría del conocimiento que asuma su estructura mediada por principios sintéticos ${ }^{64}$; la aplicación de dos principios sintéticos impediría lógicamente que el objeto conocido sea

61 Vid., con mayor detalle, HAMmER, 2005: 176-178.

62 Ya en la crítica a IHERING en los Hauptprobleme KELSEN, 1923: 502-506, parece aceptar implícitamente la corrección de una comprensión «formal» de aquello que la noción de derecho subjetivo pretendería explicar como mero derecho a reclamar el cumplimiento coactivo de la obligación (actio).

${ }_{63}$ KeLSEN, 1921: 83 y ss.

${ }^{64}$ KeLSEN, 1922: passim.; Kelsen, 1985: 8. 
el mismo. Pero precisamente la dependencia que muestra la teoría del Estado de la concepción de persona haría necesario clarificar qué se encuentra detrás de todas estas representaciones.

Parte de su crítica a la noción jurídica tradicional de persona se basa en una comprensión del concepto de ficción tomado de la filosofía de VAIHINGER, expuesta en particular en dos textos de los años 1919 y $1921^{65}$, pero que sin citas explícitas se mantuvo incluso en la segunda edición de la Teoría Pura del Derecho. VAiHINGER pretendió mostrar cómo las ciencias se sirven constantemente de designaciones y representaciones sabidamente irreales con el objeto de conocer la realidad. Este modo de proceder constituiría una «ficción». De acuerdo a su tesis, las ciencias jurídicas constituirían disciplinas paradigmáticas en la utilización del método del «como si» $(A l s-o b)$ en el conocimiento de su objeto ${ }^{66}$. Por supuesto, planteado en estos términos, la idea de ficción en las ciencias jurídicas solo podría ser inadecuada para KELSEN: como no se trata del conocimiento de un ser real en la ciencia jurídica, sino de normas, la idea misma de ficción à la VAIHINGER sería inaplicable. Las ficciones jurídicas, según KELSEN, tendrían que designar en cambio conceptos sabidamente imprecisos, pero cuya función sea permitir el conocimiento del objeto normativo en cuestión. Este sería el caso no solo de la noción de derecho subjetivo, sino también de sujeto del derecho (persona) ${ }^{67}$ y su variante más radicalmente ficticia, la personificación del ordenamiento jurídico mediante el concepto de Estado ${ }^{68}$.

El concepto de persona (y de Estado) sería así una ficción al pretender designar una realidad normativa mediante la representación de una realidad natural, para entregar «una imagen comprensible» (ein anschauliches Bild) de algo complejo ${ }^{69}$. Se trataría así de un concepto heurísticamente útil (asimilable al antropomorfismo sobre el que se construye el concepto de Dios en las religiones axiales occidentes) pero sin correlato sustantivo. Con ello, al permitir una representación sencilla de una entidad sin sustancia real como la norma mediante la ilusión de realidad, el concepto de persona cumpliría paradigmáticamente la función de una ficción en el sentido de VAIHINGER: su propia imprecisión permitiría tener una representación intuitiva de aquello que se quiere designar ${ }^{70}$. Como concepto genuinamente cognitivo, en cambio, el concepto de persona sería estructuralmente inadecuado: las ficciones, al designar indirectamente su objeto con el fin de clarificar por simplificación, tenderían a la larga a crear duplicida-

65 KeLSEN, 1919: 993 y ss., y KeLSEN, 1921: 80 y ss.

66 Vid. KeLSEN, 1919: 993 y ss.

67 KelSEN, 1919: 994 y ss.; KeLSEN, 1960: 172 y ss.

68 KELSEN, 1921: 80.

69 Ibid.

70 Analizada de cerca, la concepción de KELSEN de la persona jurídica como ficción tiene la notable elegancia de presentar una imagen convincente de una construcción conceptual cuya pretensión es exactamente contraria de aquella de la teoría que originalmente se valió de ese nombre: mientras la teoría de la ficción de SAVIGNY sostenía que la persona jurídica es la equiparación de una entidad irreal a una realidad natural (el ser humano) mediante normas (KELSEN, 1960: 176), según KELSEN el concepto de persona sería un concepto hermenéuticamente útil por la razón exactamente contraria, a saber, permitir una comprensión intuitiva más sencilla de la norma o del ordenamiento jurídico mediante la generación de la ilusión de la inclusión de una realidad natural (la «persona») en el concepto irreal de norma (KELSEN, 1919: 996) o mediante la asimilación de la estructura compleja del ordenamiento jurídico a la realidad naturalmente conocida de los deseos del ser humano (KELSEN, 1921: 80). 
des innecesarias y contradictorias, es decir, impedirían reconocer la unidad del objeto realmente designado con los conceptos de los que se valen ${ }^{71}$.

Correctamente considerado, la persona sería, en general, una parte necesaria del juicio de imputación (o, lo que es lo mismo, de la estructura de la norma $)^{72}$. Como sabemos, el juicio de imputación no es más que un acto de aplicación de una norma y consiste, de este modo, en la unión de una condición a una consecuencia: la consecuencia jurídica debe ser aplicada porque sus condiciones de aplicación se cumplieron ${ }^{73}$. Parte de esas condiciones de aplicación, lo que KELSEN denomina «imputación central» ${ }^{74}$, requerirían de identificación subjetiva tanto para atribuir la sanción ${ }^{75}$ como para poder identificar al titular de una potestad cuyo ejercicio es condición de aplicación de la norma. En ambos casos, la identificación de la persona (la «imputación central») no sería más que una parte del juicio completo de imputación («periférica»).

El concepto de persona no sería así más que una técnica de tratamiento de la imputación central. Ciertos conceptos jurídicos («persona natural», «persona jurídica») cumplirían la función de vincular individuos naturales o colectivos, constituidos bajo una forma de relación determinada, a una consecuencia jurídica, haciendo depender su procedencia de un comportamiento anterior del sujeto o mediante la atribución de la consecuencia al sujeto en cuestión ${ }^{76}$. Al no ser más que una forma de designación de condiciones de la imputación, el concepto de persona podría ser, sin embargo, disuelto en la estructura de la norma ${ }^{77}$.

Más allá de su aplicación a la teoría del Estado, la crítica a la noción (ética o sustantiva) de persona y su reconstrucción formal es sumamente esclarecedora y tiene un rendimiento crucial en las ciencias jurídicas, incluso hoy. Aquí, pese a que el tratamiento de la persona pueda ser identificado como parte de la realización negativa del programa, este tuvo además rendimientos positivos evidentes. La reconstrucción de la personalidad de KELSEN no solo permite entregar una representación más verosímil del problema de las personas jurídicas, sino que al mismo tiempo permite explicar, de mejor forma que una representación natural, las diferencias que el derecho tiende a hacer al reconocer «personalidad». Por ejemplo, el derecho tiende a tener una multiplicidad de conceptos contradictorios de personalidad en materias tales como derecho civil o derecho penal. Las reglas de capacidad (imputabilidad) son en ambas ramas del ordenamiento diversas y son al mismo tiempo diversas en relación con los distintos sub-sectores de la regulación. El conjunto de condiciones que un individuo tiene que reunir para que se le reconozcan derechos personalísimos es distinto a las condiciones

71 KELSEN, 1921: 81.

72 Vid. Dreier, 1990: 111 y ss.; HeIDEMANN, 1997: 73 y ss.

73 Vid. PAUlson, 2006: 535.

74 Kelsen, 1934a: 22 y ss. Al respecto, con mayor detalle, HeIDEMANN, 2005: 17 y ss. En la segunda edición de la Teoría Pura del Derecho (KELSEN, 1960: 154, nota a pie de página), KELSEN advierte explícitamente que la distinción original entre el concepto de imputación periférica y el concepto de imputación central ha sido reemplazado por el concepto de «atribución» (Zuschreibung), a causa de las confusiones que generaba la terminología originalmente elegida.

75 Pese a ello, según Heidemann, 2005: 22-23, esa forma de imputación podría ser completamente descrita por el concepto de imputación en sentido estricto (periférica), con lo que KELSEN no habría aplicado aquí el concepto de persona o imputación central.

76 KeLSEN, 1934a: 52 y ss.

77 Vid. también KELSEN, 1960: 122. 
que debe reunir para obligarse, y asimismo la atribución de consecuencias jurídicas a su respecto varía en distintas ramas. De la misma forma, personalidad, en el sentido de reconocimiento de un patrimonio al que se asignan distintos derechos y obligaciones, puede ser otorgada a entidades con características ontológicas completamente disímiles: individuos, asociaciones de individuos determinados o incluso asociaciones de individuos indeterminados ${ }^{78}$. El concepto natural de persona es ciego a estas variaciones y no puede sino recurrir a ficciones poco claras para superar esa ceguera inicial. Según KELSEN, esta forma de comprensión de las personas jurídicas es además lógicamente insostenible, ya que también el concepto «natural» de persona es una construcción ${ }^{79}$ : todas las diferencias que hay que hacer a su respecto demuestran que no se trata más que de construcciones jurídicas cuyo objeto es designar condiciones de aplicación de normas o la unidad de ciertos derechos y obligaciones, en la medida en que su ejercicio o el acaecimiento de las consecuencias jurídicas se encuentran unidos al comportamiento de alguien ${ }^{80}$. Parte importante de los problemas que se siguen, por ejemplo, en el reconocimiento de personalidad jurídica de asociaciones en materia penal, se esconde cuando se maneja un concepto sustantivo de persona. La respuesta «no, eso no es persona, sustancia sin embargo necesaria a la idea de responsabilidad, por lo que no puede establecerse una responsabilidad penal de personas jurídicas» oculta precisamente todo el punto, a saber, si queremos del todo reconocer la capacidad de asignar consecuencias jurídicas a asociaciones y, una vez respondido eso, en qué condiciones tiene sentido y es justo que lo hagamos ${ }^{81}$.

\subsection{El razonamiento jurídico como marco y discreción: la teoría de la interpretación de KELSEN como denuncia}

Existen pocas materias que hayan preocupado tanto a los juristas modernos como la interpretación (en fase real o hipotética de adjudicación) de las leyes. Al mismo tiempo, pocos aspectos de la obra de KELSEN parecen resultar tan insatisfactorios como su teoría de la interpretación. Su tesis aquí es tan sencilla como brutal: la interpretación no tendría nunca el carácter pretendido de operación de razonamiento controlable, sino que se trataría siempre de una operación política de decisión. Esto se explicaría analizando el contexto en el que se desarrollan las actividades de interpretación.

De acuerdo a la comprensión tradicional, la interpretación sería la operación de conocimiento de una norma al momento paradigmático de aplicar el derecho en fase de adjudicación. Como en realidad, según KELSEN, la adjudicación no es más que una fase dentro de la construcción escalonada del ordenamiento jurídico ${ }^{82}$, la interpreta-

78 Vid. KELSEN, 1960: 150 y ss.

79 KeLSEN, 1925: 9 y 81 y ss.; KeLSEN, 1960: 176.

80 KELSEN, 1960: 177.

81 El propio KELSEN advertía el punto, al dar cuenta que el problema de la capacidad de cometer delitos de las personas jurídicas no es más que un problema de la definición de nuestras operaciones de «atribución» (Zuschreibung) de responsabilidad penal (KELSEN, 1960: 185). Una concepción similar de la persona, aunque no limitada al puro reflejo de normas positivas, puede encontrarse en concepciones tan distintas como JAKOBS, 2008: 28 y ss.; o GÜNTHER, 2005: 102 y ss.

82 Así tematizado desde un inicio en KELSEN, 1934b: 1113. El artículo Zur Theorie der Interpretation fue, en lo esencial, reproducido posteriormente al final de la segunda edición de la Teoría Pura del Derecho. Ambas versiones tienen, sin embargo, variaciones en lo relativo a su redacción. 
ción (auténtica) ${ }^{83}$ se dejaría caracterizar más ampliamente como el procedimiento de atribución de contenido a normas que otorgan potestades para crear otras. En todos estos casos, el conocimiento del sentido de la norma sería necesario porque el alcance de la potestad para crear norma depende de este; la interpretación serviría de esta forma para determinar el conjunto de normas posibles que su aplicador puede crear. La norma a interpretar sería así parte de la fuente de la competencia para crear el acto normativo en cuestión; ella simplemente fijaría las condiciones bajo las cuales el sujeto puede realizar un acto normativo y, con ello, la extensión posible de ese acto. Por ello, sería lógicamente imposible que la norma fijara por completo el contenido del acto de creación del derecho, ya que sin concesión de un mínimo de discreción, el otorgamiento de la potestad para crear una nueva regla carecería de sentido.

Una comprensión de esta clase es, por cierto, inaceptable para la dogmática jurídica. Tradicionalmente, la teoría de la interpretación tiene por objeto tematizar la justificación de la decisión interpretativa. Esa justificación tiende a construirse bajo la idea de conocimiento: la atribución de sentido sería correcta porque ese es el contenido de la norma. La interpretación sería, de esta forma, el momento paradigmático de conocimiento jurídico ${ }^{84}$. En KELSEN, probablemente el positivista más preocupado por la generación de una teoría del conocimiento jurídico, la interpretación aparece caracterizada, al contrario, por oposición al conocimiento jurídico; ella es descrita como una operación de pura decisión ${ }^{85}$. Esto es algo que tradicionalmente ha decepcionado explícitamente a los teóricos del derecho en el acercamiento a la obra de KELSEN $^{86}$.

De acuerdo a KELSEN, el carácter necesario del aspecto volitivo de la interpretación se vería confirmado al mirar el tipo de problemas al que se enfrenta la teoría tradicional de la interpretación. Su problema crucial, al menos en la forma en que ha sido tematizada durante el siglo Xx, es la indeterminación: cuando el sentido de una norma no es unívoco, elegir uno de los sentidos posibles sería necesario. De acuerdo a KELSEN, esto se puede traducir a la regulación de la relación entre norma de origen, potestad y norma creada. Cuanto mayor sea la indeterminación de la norma que confiere potestades normativas, más amplio sería el marco de actos normativos válidos que pueden ser creados en aplicación de la norma interpretada, con lo que el aplicador/ creador de las normas tendría mayores posibilidades de elección. Pero ese momento de indeterminación sería necesario: en la interpretación, se trataría de una elección entre varios sentidos posibles dentro de un marco otorgado por la disposición (que

83 Es importante tener en cuenta que el concepto de interpretación auténtica de KELSEN se construye por analogía con el concepto al que tradicionalmente se designa como tal. Esa analogía, sin embargo, tiene pretensiones de desafío. La interpretación auténtica es usualmente entendida como aquella que vincula al órgano vinculado a la ley (el juez) y, en ese sentido, constituye ella misma una norma. El concepto tiende a ser utilizado respecto a la interpretación hecho por el legislador de las leyes: el otorgamiento de sentido que el propio legislador ha efectuado tiene que ser acatado por el juez. La interpretación auténtica se distingue, de esta forma, de la interpretación judicial. KELSEN utiliza el concepto de interpretación auténtica manteniendo la representación que anima a la distinción tradicional, a saber, distinguir entre formas de interpretación vinculantes y no vinculantes. Pero si eso es así, también la interpretación judicial sería auténtica: ella es una fuente que permitiría justificar la sentencia y, en ese sentido, una norma creada por el tribunal y que vincula a quienes deben aplicarla.

${ }_{84}$ Así, por ejemplo, GUASTINI, 1999: 256-257.

85 Así también MerKL, 1917a: 956-957.

86 Guastini, 1999: 257; NúÑ̃z Vaquero, 2014: 423 y ss. 
en realidad es norma) a ser interpretada y cuya extensión dependería de su grado de indeterminación ${ }^{87}$.

La concepción de la interpretación de KELSEN parece así decepcionante por varias razones. En primer lugar, ella renuncia por completo a tematizar el proceso de atribución de sentido y de justificación de esa atribución dentro del marco fijado, según él, por la norma. La idea de interpretación racionalmente justificable como correcta (la «única solución correcta») es así reducida por KELSEN a la forma de un autoengaño ${ }^{88}$. Los criterios de interpretación, en la centenaria disputa entre concepciones objetivas, subjetivas y sus variantes, solo servirían para crear la apariencia de justificación de resultados posibles, equivalentes entre sí, en el marco de la creación de una norma inferior.

Buena parte de la defraudación producida aquí por KELSEN encuentra su explicación, sin embargo, en las expectativas que tienden a ser puestas por los teóricos del derecho al momento de analizar una teoría de la interpretación. En ellas, se tiende a buscar explicaciones analíticas del proceso de interpretación, que permitan esclarecer al menos los presupuestos o la estructura de una argumentación de interpretación, o discusiones respecto al mérito de los distintos métodos de interpretación. Como a la dogmática le interesan ante todo disputas de esta clase, es asumido como normal que una teoría de la interpretación deba entregar respuestas a estas preguntas. La teoría de la interpretación de KELSEN tiene la forma, en cambio, de una denuncia; para el jurista preocupado ante todo de la interpretación y aplicación de leyes, la única función que correctamente se le puede atribuir a la teoría de KELSEN es la de una provocación ${ }^{89}$. La teoría pura del derecho dejaría de asumir aquí la postura del escéptico moderado en búsqueda de mayor precisión y que ofrece equivalentes funcionales a los conceptos de derecho subjetivo o persona, y pasaría a ser así un verdadero nihilista.

Considerada de cerca, sin embargo, la denuncia que supone la teoría de la interpretación de KELSEN tiene también otro objeto y no es puramente destructiva. No se trata (solo) de una pretensión nihilista de privar a la ciencia del derecho de cualquier mérito cognitivo, sino de una pretensión constructiva de denuncia de ciertas fijaciones nocivas con el objeto de re-caracterizar al derecho sin esas fijaciones. Esas fijaciones nocivas pueden ser reducidas a dos ideas: el exceso de fijación en la idea de que el derecho se conoce y se aplica solo al momento de la adjudicación y, por otro lado, la ceguera frente a la dinámica del derecho. Frente a la noción tradicional de que interpretación es conocimiento del contenido de la norma en la interpretación, KELSEN y su escuela pretendían así redefinir el centro de interés de la interpretación en la determinación de la relación entre norma que otorga potestades y norma creada mediante esas potestades, es decir, pretendía mostrar la integración de la interpretación en la dinámica del derecho ${ }^{90}$. La teoría de la interpretación de KELSEN es de este modo una demostración de la forma en que aquello que es caracterizado como el momento de la interpretación en la comprensión tradicional —la adjudicación — se inserta en el

\footnotetext{
87 KELSEN, 1960: 347-348.

88 Kelsen, 1934b: 1114 y ss.; KeLSEN, 1960: 350.

89 Así también LePsius, 2013: 257 y ss.

90 Similar LEPSIUS, 2013: 258.
} 
funcionamiento constante del derecho en reproducirse y transformarse y, en lo que les interesa ante todo a los juristas, en pasar de grados de abstracción amplios a una determinación suficiente para el ejercicio de la coacción ${ }^{91}$. La interpretación es caracterizada, así, como la operación que permite que organismos con distintas potestades normativas se relacionen entre sí en la construcción escalonada del ordenamiento jurídico. La interpretación aparece de esta forma directamente caracterizada como «el procedimiento espiritual que acompaña a la aplicación del derecho en su avance desde estadios superiores a estadios inferiores» (KELSEN, 1934b: 1113; 1960: 346).

La crítica a la concepción tradicional de la interpretación permite apreciar sus falencias y su ceguera frente al sistema complejo y constantemente cambiante que constituye al derecho: el derecho no es el conjunto estático de textos, cuyo conocimiento por parte del adjudicador o del jurista implica conocimiento total de este y de sus respuestas. El derecho es, en cambio, un mundo conjunto constantemente construido por una multiplicidad de actores. Ese mundo conjunto se construye por medio del reconocimiento de potestades y por el reconocimiento de la aplicación de esas potestades. Entender ello, entender al derecho como sistema dinámico, requiere desprenderse de la ilusión estática creada por la dogmática para permitir su propio funcionamiento. La brutal teoría de la interpretación de KELSEN tiene por objeto forzar a abrir los ojos para abandonar esta asunción común.

La teoría de la interpretación cumple de esta forma el rol de umbral entre el aspecto negativo y el aspecto positivo de la realización del programa de KELSEN. Por una parte, se trata de una crítica radical a la noción tradicional de interpretación y, con ello, a la auto-comprensión tradicional de la ciencia del derecho. Pero, por otra parte, la teoría de la interpretación de KELSEN es parte del desarrollo de una explicación de la forma en que debe ser comprendido el derecho en tanto sistema dinámico. Ella tiene un rol pragmático ante todo negativo - y por ello ha sido constantemente objeto de polémica - pero es re-caracterizada en la fase de realización positiva del derecho al reconstruirlo como sistema dinámico en cambio constante. El carácter total de la obra de KELSEN se muestra en esta interdependencia entre sus aspectos positivos y negativos.

\section{BIBLIOGRAFÍA}

\section{Textos de Hans Kelsen y de Adolf MERKL ${ }^{92}$}

Kelsen, H., 1913: «Rechtsstaat und Staatsrecht», en Klecatsky, Marcic y Schambeck, Die Wiener Rechtstheoretische Schule, t. II, Viena, 2010, 1247-1253.

- 1916: «Die Rechtswissenschaft als Norm- oder Kulturwissenschaft», en KLECATSKY, MARCIC y SCHAMBECK, Die Wiener Rechtstheoretische Schule, t. I, Viena, 1968, 77-119.

- 1919: «Zur Theorie der juristischen Fiktionen», en KLECATSKY, MarCiC y SCHAMBECK, Die Wiener Rechtstheoretische Schule, t. II, Viena, 2010, 993-1014.

91 Enfático MERKL, 1917a: 957; 1922: 1325.

92 Los textos de KELSEN y MERKL son citados indicando el año de publicación original de la edición en alemán correspondiente, lo que aparece en la lista bibliográfica entre paréntesis a continuación del nombre. En su caso, la traducción o reimpresión específica es indicada normalmente. 
- 1921: «Das Verhältnis von Staat und Recht im Lichte der Erkenntniskritik», en KLECATSKY, MARCIC y SCHAMBECK, Die Wiener Rechtstheoretische Schule, t. I, Viena, 2010, 77-119.

- 1922: «Rechtswissenschaft und Recht», en S. PAULSON (ed.), Die Rolle des Neukantianismus in der Reinen Rechtslehre, Aalen, 1988, 279-411.

- 1923: Problemas capitales de la teoría jurídica del Estado, 2. ${ }^{a}$ ed., México D. F., 1987.

- 1925: Teoría General del Estado, México D. F., 2005.

- 1928: «Die philosophischen Grundlagen der Naturrechtslehre und des Rechtspositivismus», en KleCATSKY, MaRCIC y SCHAMBECK, Die Wiener Rechtstheoretische Schule, t. I, Viena, 2010, 231-287.

- 1930: Der Staat als Integration, Viena, 1930.

- 1934a: Reine Rechtslebre, 1. ${ }^{a}$ ed., Viena, 1934 (reimpresión Tubinga 2008).

- 1934b: «Zur Theorie der Interpretation», en KleCATSKy, MARCiC y SCHAMBECK, Die Wiener Rechtstheoretische Schule, t. II, Viena, 2010, 1113-1121.

- 1960: Reine Rechtslehre, 2. ${ }^{a}$ ed., Viena, 1960 (reimpresión 1992).

MerKL, A. J., 1917: «Das Recht im Lichte seiner Anwendung», en KleCATSKY, MarCiC y SchAMвECK, Die Wiener Rechtstheoretische Schule, t. I, Viena, 2010, 955-982.

- 1922: «Gesetzrecht und Richterrecht», en Die Wiener Rechtstheoretische Schule, t. II, Viena, 2010, 1323-1330.

\section{Literatura secundaria y complementaria citada}

Alexy, R., 1992: Begriff und Geltung des Rechts, Friburgo en Brisgovia-Múnich.

Buligyn, E., 2005: «Das Problem der Geltung bei Kelsen», en Paulson y StOlleis (eds.), Hans Kelsen, Tubinga, 80-95.

DreIER, H., 1990: Rechtslehre, Staatssoziologie und Demokratietheorie bei Hans Kelsen, 2." ed., Baden-Baden, 1990.

GARZÓN VALDÉS, E., 2000: El velo de la ilusión. Apuntes sobre una vida argentina y su realidad política, Buenos Aires.

GUASTINI, R., 1999: Distinguiendo. Estudios de teoría y metateoría del derecho, Barcelona.

GÜNTHER, K., 2005: Schuld und kommunikative Freiheit, Fráncfort del Meno, 2005.

HAMmER, S., 2005: «Braucht die Rechtstheorie einen Begriff vom subjektiven Recht? Zur objektivistischen Auflösung des subjektiven Rechts bei Kelsen», en PAULSON y STOLLEIS (eds.), Hans Kelsen, Tubinga, 176-190.

HeIDEmann, C., 1997: Die Norm als Tatsache. Zur Normentheorie Hans Kelsens, 1. ${ }^{a}$ ed., Baden-Baden.

— 2005: «Der Begriff der Zurechnung bei Hans Kelsen», en Paulson y STOLLEIS (eds.), Hans Kelsen, Tubinga, 17-34.

- 2000: «The creation of normative facts», en Law and Philosophy 2000, 263-281.

HelleR, H., 1934: «Die Krisis der Staatslehre», en el mismo, Gesammelte Schriften in drei Bänden, 2. ${ }^{\text {a }}$ ed., t. 3, 1992, 3 y ss.

JakовS, G., 2008: Norm, Person, Gesellschaft. Vorüberlegungen zu einer Rechtsphilosophie, 3. ${ }^{a}$ ed., Berlin.

Kersting, W., 2000: «Staatsphilosophie und weimarer Staatsrechtslehre», en el mismo, Politik und Recht, Gotinga, 394-430.

KorB, A., 2010: Kelsens Kritiker, Tubinga.

Korioth, S., 2013: «Kelsen im Diskurs - Die Weimarer Jahre», en JeSTAEDT (ed.), Kelsen und die deutsche Staatsrechtslehre, Tubinga, 2013, 29-46. 
LePsiUs, O., 2013: «Hans Kelsen und die Pfadabhängigkeit in der deutschen Staatsrechtslehre», en JestaedT (ed.), Hans Kelsen und die deutsche Staatsrechtslebre, Tubinga, 241-266.

MÖLlERS, C., 2008: Der vermisste Leviathan, Fráncfort del Meno.

NúÑEZ Vaquero, A., 2014: «Kelsen en la encrucijada: ciencia jurídica e interpretación del derecho», en Ius et Praxis, año 20, núm. 2, 415-442.

PAulson, S., 1990: «Läßt sich die Reine Rechtslehre transzendental begründen?», en Rechtstheorie, 1990, 155-179.

- 2005: «Zwei radikale Objektivierungsprogramme in der Rechtslehre Hans Kelsens», en Paulson y StOlleis (eds.), Hans Kelsen, Tubinga, 191-220.

- 2006: «Der Normativismus Hans Kelsens», en Juristen Zeitung, 2006, 529-536.

ReNZIKOwsKI, J., 2001: «Normentheorie als Brücke zwischen Strafrechtsdogmatik und Allgemeiner Rechtslehre», en ARSP, 87, 2001, 110-125.

RiCKERT, H., 1926: Kulturwissenschaft und Naturwissenschaft, 7. ${ }^{\text {a }}$ ed., Tubinga, 1926.

RuIz MANero, J., 2010: «Cincuenta años después de la segunda edición de la Reine Rechtslebre: sobre el trasfondo de la Teoría Pura del Derecho y qué queda de ella», en DOXA, Cuadernos de Filosofía del Derecho, núm. 33, 37-46.

SEARLE, J., 2010: Making the Social World. The Structure of Human Civilization, New York.

STAMMLER, R., 1925: Rechtsphilosophische Abhandlungen und Vorträge. Erster Band, Charlottenburg, reimpresión Aalen, 1970.

VINX, L., 2007: Hans Kelsen's pure theory of law. Legality and legitimacy, New York.

WilenMAnN, J., 2014: «El camino de la teoría pura del derecho», en Revista de Estudios de la Justicia, núm. 20, 34-66. 